ARTICLE OPEN

Check for updates

\title{
Rapid assessment of structural and compositional changes during early stages of zirconium alloy oxidation
}

Elizabeth J. Kautz (D) ${ }^{1}$, Bharat Gwalani $\mathbb{D}^{2}$, Sten V. M. Lambeets $\mathbb{D}^{3}$, Libor Kovarik ${ }^{2}$, Daniel K. Schreiber $\mathbb{D}^{4}$, Daniel E. Perea $\mathbb{D}^{3}$, David Senor ${ }^{4}$, Yi-Sheng Liu ${ }^{5}$, Anil K. Battu ${ }^{3}$, Kuo-Pin Tseng ${ }^{6}$, Suntharampillai Thevuthasan ${ }^{3}$ and Arun Devaraj (iD ${ }^{2 凶}$

A multimodal chemical imaging approach has been developed and applied to detail the dynamic, atomic-scale changes associated with oxidation of a zirconium alloy (Zircaloy-4). Scanning transmission electron microscopy, a gas-phase reactor chamber attached to an atom probe tomography instrument, and synchrotron-based X-ray absorption near-edge spectroscopy were employed to reveal morphology, composition, crystal, and electronic structure changes that occur during initial stages of oxidation at $300{ }^{\circ} \mathrm{C}$. Oxidation was carried out in $10 \mathrm{mbar}_{2}$ gas for short exposure times of 1 and $5 \mathrm{~min}$. A multilayered oxide film with a cubic ZrO adjacent to the oxide/metal interface, a nanoscopic transition region with a graded composition of $\mathrm{ZrO}_{2-x}($ where $0<x<1)$, and tetragonal $\mathrm{ZrO}_{2}$ in the outermost oxide were formed. Partitioning of the major alloying element (tin) to the oxide/metal interface and heterogeneously within the oxide accompanied the development of the layered oxide. Our work provides a rapid, highthroughput approach for detailed characterisation of initial stages of zirconium alloy oxidation at an accelerated time scale, with implications for several other alloy systems.

npj Materials Degradation (2020)4:29; https://doi.org/10.1038/s41529-020-00133-6

\section{INTRODUCTION}

Alloys applied in nuclear reactors ${ }^{1,2}$, gas turbines ${ }^{3,4}$, heterogeneous catalysis ${ }^{5,6}$, automotive internal combustion engines ${ }^{7}$, and electronic devices ${ }^{8,9}$ are routinely exposed to high-temperature, corrosive, and oxidising environments. Oxidation of alloys in service can degrade material properties and performance, raising significant safety and economic concerns. Hence, a comprehensive understanding of oxidation mechanisms is necessary to evaluate applicability of a material in a desired environment. Characterising one or more oxides formed during the initial stages of oxidation is a significant challenge because oxidation of alloying elements is simultaneous with the nucleation and growth of metastable phases ${ }^{10,11}$. Further, the composition across buried oxide/metal interfaces can also change, often heterogeneously, depending on the crystallographic orientation of the base metal grains below ${ }^{6}$, requiring a spatially resolved analysis of such changes.

Zirconium ( $\mathrm{Zr}$ ) alloys are widely used in nuclear applications, most commonly as nuclear reactor fuel cladding in pressurised water reactors ${ }^{12,13}$, and as a hydrogen isotope absorbing material in tritium producing burnable absorber rods ${ }^{14,15}$. Zr alloys have been selected for these applications because they offer a favourable combination of mechanical durability, corrosion resistance, and a low thermal neutron cross-section ${ }^{16,17}$. However, oxidation and hydrogen pickup can significantly affect the integrity of these alloys in various environments, such as normal reactor operating conditions and short- and long-term storage (in spent fuel storage pools or canisters) ${ }^{2}$. Since oxidation of these alloys has serious implications for environmental and economic viability of nuclear energy, a deeper understanding of oxide evolution and oxidation mechanisms is needed.
Most of our understanding of $\mathrm{Zr}$ alloy oxidation comes from long-term autoclave experiments, ranging from tens to hundreds of days, involving weight gain measurements and post-test, ex situ microscopy ${ }^{2}$. These measurements are fit to a power-law relationship, with oxide thickness proportional to $t^{n}$, where $t$ is time and $n$ is a constant between 0.25 and $0.50^{18}$. The 'initial' oxide layer (referred to as 'pre-transition') is adherent and protective. Once the oxide thickness reaches a critical value $(\sim 2-3 \mu \mathrm{m})$, the protective characteristic is lost, and oxidation proceeds rapidly, essentially resetting the power-law growth rate $^{19-21}$. This sudden increase in oxidation rate is referred to as a kinetic transition. Some $\mathrm{Zr}$-based alloys experience cyclic kinetics (with multiple transitions), while others have an initially protective oxide film, followed by breakaway corrosion and oxide spallation ${ }^{2}$. It has been hypothesised that stress accumulation in the oxide layer leads to the development of cracks and pores that act as short-circuit paths for oxygen diffusion to the oxide/metal interface, leading to accelerated corrosion ${ }^{2,22,23}$. Although models and computational studies have explored this topic ${ }^{24,25}$, reported experimental observations in $\mathrm{Zr}$ alloys cannot be described by such models or fundamental theories (e.g., Wagner's theory of parabolic oxide growth rate $^{26}$ ) alone. The topic of $\mathrm{Zr}$ alloy oxidation is further complicated by the numerous oxide compositions and structures reported in literature, with several allotropic transformations possible in the oxide ${ }^{19,27}$. Thus the mechanisms governing the evolution of composition and structure across the oxide/metal interface and how the protective character of the oxide film is lost remain elusive ${ }^{2}$.

The application of high-resolution analytical techniques, such as atom probe tomography (APT) and scanning transmission electron microscopy (STEM)/electron energy loss spectroscopy, has helped improve the understanding of structure, composition,

\footnotetext{
${ }^{1}$ National Security Directorate, Pacific Northwest National Laboratory, Richland, WA, USA. ${ }^{2}$ Physical and Computational Sciences Directorate, Pacific Northwest National Laboratory, Richland, WA, USA. ${ }^{3}$ Earth and Biological Sciences Directorate, Pacific Northwest National Laboratory, Richland, WA, USA. ${ }^{4}$ Energy and Environment Directorate, Pacific Northwest National Laboratory, Richland, WA, USA. ${ }^{5}$ Advanced Light Source, Lawrence Berkeley National Laboratory, Berkeley, CA, USA. ${ }^{6}$ Department of Materials Science and Engineering, University of Illinois Urbana-Champaign, Champaign, IL, USA. ${ }^{凶}$ email: arun.devaraj@pnnl.gov
} 
and chemical states across oxide/metal interfaces after long-term oxidation ${ }^{18,22,27-33}$. Critical to improved mechanistic understanding of Zr alloy oxidation is tracking the early stages of oxide film formation. However, such analyses have received relatively less attention given the difficulties in preserving oxide/metal interfaces. High-resolution in situ/operando transmission electron microscopy (TEM) is emerging as a way to analyse atomic-scale structural changes near alloy surfaces during high-temperature oxidation $^{11,34-36}$. Nevertheless, such TEM studies have inherent challenges when quantitatively analysing composition of light elements and low concentrations of alloying or impurity elements, particularly across complex interfaces. The recently developed reaction chambers attached to the vacuum systems of APT instruments have been used to study composition changes of oxide layers. These chambers have demonstrated their usefulness in analysing near-surface compositional changes during oxidation of catalyst materials such as $\mathrm{Pt}-\mathrm{Rh}, \mathrm{Pt}-\mathrm{Ru}, \mathrm{Pt}-\mathrm{Ru}-\mathrm{Rh}, \mathrm{Pd}-\mathrm{Rh}$, and $\mathrm{Rh}^{5,6,37}$ and $\mathrm{Mg}$ alloys ${ }^{38}$.

In an effort to uncover atomic-scale changes that contribute to oxidation behaviour in the pre-transition regime and gain insight into characteristics of the protective oxide formed, we investigated the initial oxide formation and its evolution on zirconium alloy (Zircaloy-4) at $300^{\circ} \mathrm{C}$ in a controlled oxygen gas $\left(\mathrm{O}_{2}\right)$ environment. Ultrahigh vacuum (UHV) transfer of the sample between an environmental reaction chamber and the APT analysis chamber enables cyclic oxidation and analysis of the same sample with direct site registry, in contrast with conventional ex situ approaches where different areas are analysed in each experiment $^{39}$. The APT results were coupled with STEM analysis of oxidised APT needles for spatially resolved structural analysis of the oxide phases. Synchrotron-based X-ray absorption near-edge spectroscopy (XANES) provided insights into electronic structure changes. The collective insights from all three experimental techniques provide a comprehensive understanding of structural, compositional, and chemical state changes during the early stages of Zircaloy-4 oxidation. The approach utilised here provides a rapid, high-throughput methodology for detailing early stages of alloy oxidation, relevant to several systems and application areas.

\section{RESULTS}

Initial oxide formation at $300^{\circ} \mathrm{C}$

The native oxide formed on needle samples during atmospheric transfer from the focused ion beam (FIB) microscope to the APT microscope (Fig. 1) had a stoichiometry close to that of $\mathrm{Zr}_{3} \mathrm{O}$. The O:Zr ratio was $\sim 1: 3.5$ ( $\sim 29$ at. \% O), which is consistent with the
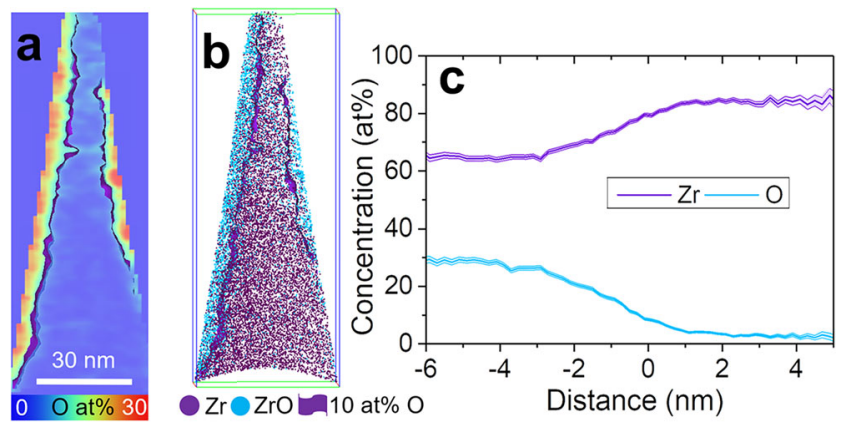

Fig. 1 Compositional analysis of the Zircaloy-4 needle before oxidation. a 2-D contour plot for $\mathrm{O}$, where concentration is shown on the colour scale to vary between 0 and 30 at. \%. b 3-D element distribution map showing $\mathrm{Zr}$ (purple dots) and $\mathrm{ZrO}$ (light blue dots) ions and a 10 at. \% O isoconcentration surface (purple surface). A 10 at. \% $\mathrm{O}$ isoconcentration surface is shown in purple in $\mathbf{a}, \mathbf{b}$. c Proximity histogram for $\mathrm{Zr}$ and $\mathrm{O}$ concentrations across the oxide/ metal interface. solid solubility limit of $\mathrm{O}$ in the $\mathrm{a}-\mathrm{Zr}$ matrix ${ }^{40}$ and with previously reported APT analysis of $\mathrm{Zr}$ oxides ${ }^{27}$. The native oxides on all needle samples were removed via field evaporation in the APT microscope, exposing an oxide-free top surface prior to oxidation experiments in an environmental reaction chamber.

Next, this same needle was oxidised for $1 \mathrm{~min}$ at $300{ }^{\circ} \mathrm{C}-10.35 \mathrm{mbar}_{2}$ and characterised thereafter using APT (Fig. 2). The two-dimensional (2-D) compositional map of $\mathrm{O}$ in Fig. 2a highlights the oxidation being most prominent at the tip apex, up to a maximum thickness of $8 \mathrm{~nm}$. The oxide/metal interface is represented by an isoconcentration surface at 30 at. \% $\mathrm{O}$ (Fig. 2b). A quantitative proximity histogram across a subvolume of this interface (white dashed outline in Fig. $2 b$ ) in Fig. $2 c$ shows that the $\mathrm{O}: \mathrm{Zr}$ ratio throughout the oxide is approaching 1:1, suggesting a nearly stoichiometric ZrO phase. The interfacial width (calculated as the distance between $O$ concentrations of 20 and 80 at. \% of the maximum in the proximity histogram given in Fig. $2 \mathrm{c}$ ) is $4 \mathrm{~nm}$, whereas the physical roughness (defined as rootmean-square roughness) is $1.02 \mathrm{~nm}$. Roughness values were calculated from a cube region of interest $(30 \times 40 \times 80 \mathrm{~nm})$ placed in the centre of the reconstruction, containing the oxide/metal interface, with voxel size $1 \times 1 \times 1 \mathrm{~nm}$ and delocalisation parameters of $3 \mathrm{~nm}(x) \times 3 \mathrm{~nm}(y) \times 1.5 \mathrm{~nm}(z)$.

Oxygen penetration into the base alloy below the oxide-metal interface is evident in the 2-D concentration plot of Fig. 2a. White arrows in Fig. $2 \mathrm{a}$ indicate local regions of $\mathrm{O}$ enrichment within the alloy and highlight the nonuniformity of $O$ penetration.

\section{Oxide evolution after $5 \mathrm{~min}$ at $300^{\circ} \mathrm{C}$}

Further development of the oxide film was studied by analysing the oxide layers after exposing the APT needle at $300^{\circ} \mathrm{C}$ for $5 \mathrm{~min}$ at $10.35 \mathrm{mbar}_{2}$ (Fig. 3). The mass-to-charge spectra before and after oxidation experiments are provided in Supplementary Fig. 1. The 30 and 55 at. \% $\mathrm{O}$ isoconcentration surfaces (light blue and green, respectively) overlaid on the 2-D concentration map of $O$ in Fig. $3 a$ and the ionic view in Fig. $3 b$ are markers for the oxide/ metal interface ( 30 at. $\% \mathrm{O}$ ) and the compositional transition in the oxide (55 at. \% O). The oxide-metal interface has a root-meansquare roughness of $1.48 \mathrm{~nm}$, while the 55 at. \% O isoconcentration surface has a root-mean-square roughness of $1.93 \mathrm{~nm}$, which serves as a proxy for the diffuse $\mathrm{ZrO} / \mathrm{ZrO}_{2}$ interface. Note that the oxide layer formed on the base alloy needle is asymmetrical (Fig. 3a, b). The compositional partitioning across the two different oxide/metal interface facets, identified using the 30 at. \% 0 isoconcentration surfaces, were calculated using proximity histograms. The specific facet subvolumes selected for proximity histograms are marked by white dashed outlines in Fig. 3b. These
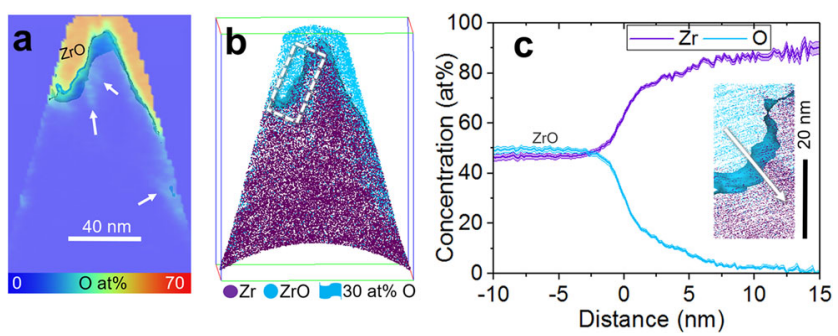

Fig. 2 Compositional analysis of Zircaloy-4 after oxidation at $300^{\circ} \mathrm{C}-10.35$ mbar $\mathrm{O}_{2}-1$ min. a 2-D contour plot for $O$, where concentration is shown on the colour scale to vary between 0 and 70 at. $\% 0$, where white arrows identify regions of non-uniform $\mathrm{O}$ penetration in the base alloy, b 3-D element distribution map showing $\mathrm{Zr}$ (purple dots) and $\mathrm{ZrO}$ ions (light blue dots), and a 30 at. $\% \mathrm{O}$ isoconcentration surface (light blue). c Proximity histogram for $\mathrm{Zr}$ and $\mathrm{O}$ concentrations across the oxide/metal interface. Inset in c shows the subvolume analysed, which corresponds to the region outlined by the dashed line in $\mathbf{b}$. 

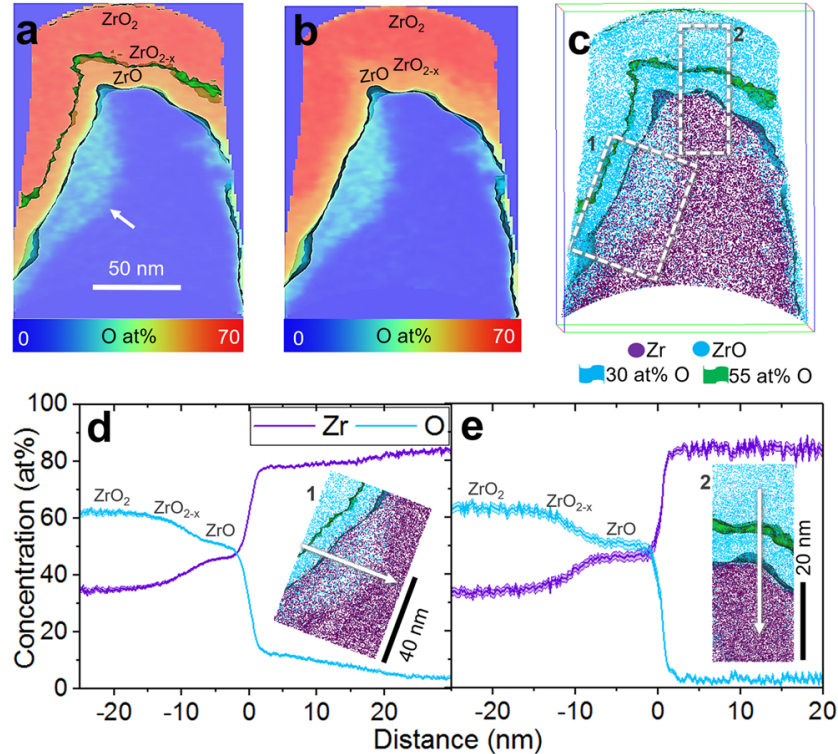

Fig. 3 Compositional analysis of Zircaloy-4 after oxidation at $300^{\circ} \mathrm{C}-10.35 \mathrm{mbar} \mathrm{O}_{2}-\mathbf{5} \mathrm{min}$. a 2-D contour plot for $\mathrm{O}$ at. \%, where the colour scale indicates that concentration varies between 0 and 70 at. \%. Isoconcentration surfaces of 30 at. \% O (light blue surface) and 55 at. \% O (green surface) are provided to highlight the layered composition. b 2-D contour plot for $\mathrm{O}$ at. \% without a 55 at. \% O isosurface with same $O$ concentration scale as a. c 3-D element distribution map showing $\mathrm{Zr}$ (purple dots) and ZrO (light blue dots) ions, with 30 at. $\% \mathrm{O}$ and 55 at. \% O isoconcentration surfaces. c Proximity histograms for $\mathrm{Zr}$ and $\mathrm{O}$ concentration across the oxide/ metal interface for the two regions outlined in c. Dashed white lines and numbers in c indicate the subvolumes that were used to generate proximity histograms shown in d, e. Insets in d, e correspond to the regions labelled 1 and 2 in c.

subvolumes are shown as insets within the corresponding proximity histograms in Fig. $3 c$, d.

The composition profiles show a layered oxide structure that appears to be, from base metal outward, $\mathrm{ZrO}, \mathrm{ZrO}_{2-x}(0<x<1)$, and $\mathrm{ZrO}_{2}$ phases. The inner $\mathrm{ZrO}$ layer is conformal with the metal surface and uniformly $\sim 7 \mathrm{~nm}$ thick, whereas the outermost $\mathrm{ZrO}_{2}$ layer varies between 7 and $15 \mathrm{~nm}$ thick. These two layers are separated by an intermediate layer of $\mathrm{ZrO}_{2-x}(\sim 5 \mathrm{~nm}$ thick). The O: $\mathrm{Zr}$ ratio varies monotonically from $\mathrm{ZrO}$ to $\mathrm{ZrO}_{2}$ through this region. This monotonic variability in $\mathrm{O}: \mathrm{Zr}$ through the intermediate oxide seems invariant to direction of analysis in the reconstructed data across all facets, suggesting that it is a real feature of the oxide structure and not a field evaporation artefact.

APT also reveals that the oxygen concentration in the base alloy can vary across the oxide/metal interface. For example, in Fig. 3c the $O$ concentration declines from 12 at. \% to 5 at. \% over $23 \mathrm{~nm}$. This region of higher $\mathrm{O}$ concentration (relative to 1.2 at. \% $\mathrm{O}$ in the base alloy) is indicated with a white arrow in Fig. 3a. Conversely, in the subvolume shown in the inset of Fig. $3 d$ taken from another facet, the interfacial width of the oxide-metal interface is $<1 \mathrm{~nm}$.

Zr-based alloys are known to form hydrides readily, and hydride formation and oxidation are reported to be interrelated phenomena ${ }^{2}$; hence, hydrogen $(H)$ in the Zircaloy- 4 base alloy and oxide layers was also considered in APT analysis. Results, reported in Supplementary Fig. 2, show that $\mathrm{H}$ concentrations in the base alloy were similar before and after oxidation, and $\mathrm{H}$ in the oxide was minimal ( 2-4 at. \%).

Structural characterisation of the oxide layers

Correlative STEM analysis was conducted to investigate the structure of the oxide phases formed on the APT needle sample
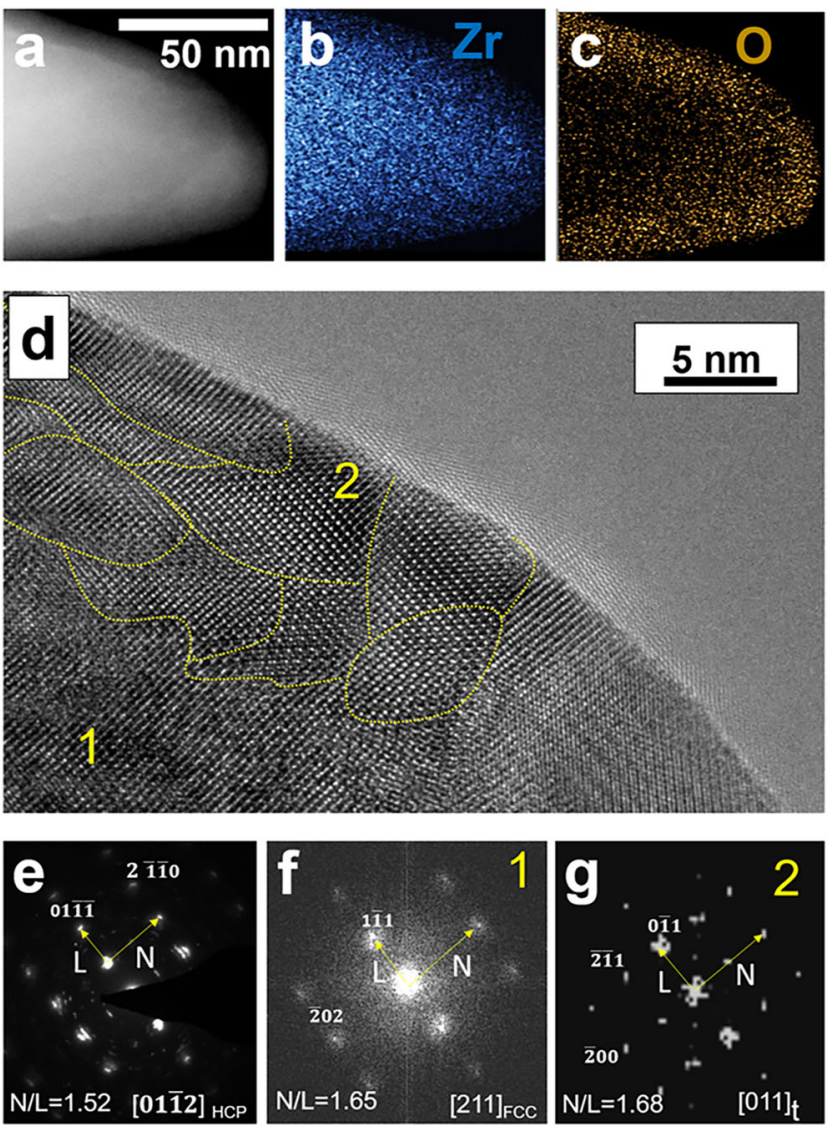

Fig. 4 Structure and morphology of the initial oxide layer formed on Zircaloy-4. a HAADF-STEM image showing the oxide film formed on the APT needle after 5 -min exposure at $300^{\circ} \mathrm{C}-10.35 \mathrm{mbar}_{2}$. b, c EDS maps of $\mathrm{Zr}$ and $\mathrm{O}$, respectively. d High-resolution (HR)-TEM image of the oxide formed on the outer edge of the needle. e SADP, with brightest spots from the Zircaloy- 4 matrix aligned with the [0112] HCP zone axis. f, $\mathbf{g}$ Indexed FFT images from grains labelled ' 1 ' and ' 2 ' in $\mathbf{d}$, respectively.

after $5 \mathrm{~min}$ of oxidation at $300^{\circ} \mathrm{C}$. The oxide layer is $20-25 \mathrm{~nm}$ thick, polycrystalline with equiaxed grains of size $\sim 5-10 \mathrm{~nm}$, and encapsulates the specimen apex and sides, as seen in Fig. $4 a-c$. The yellow dotted lines in Fig. 4d highlight several discrete oxide grains. The atom probe needle was tilted in TEM to align with a low-index zone axis. Lattice spacings and crystal symmetry were identified for the outer regions of the oxide layer with the needle aligned to the [0112] zone axis $(N / L=1.52$, where $N=2.55$ and $L=1.68$ ) in the hexagonal close packed (HCP) structure of Zircaloy-4. A selected area diffraction pattern taken from the base alloy is shown in Fig. 4e. The lattice parameters of the base alloy were estimated to be $a=3.36 \AA$ and $c=5.28 \AA$. The values for $a$ and $c$ are $\sim 4 \%$ higher than those reported in the literature $(a=$ $3.23 \AA$ and $c=5.15 \AA)^{41}$, which may be attributed to lattice expansion (and thus volume expansion) associated with oxidation.

As we examined the nanograins near the periphery of the needle sample, we found that there were several overlapping oxide grains. Grains labelled ' 1 ' and ' 2 ' in Fig. $4 d$ were analysed by examining their respective fast Fourier transformations (FFTs), provided in Fig. 4f, $\mathrm{g}$. The atom spacing and crystal symmetry in grain 1, shown in Fig. 4f, indicate the cubic crystal structure $(N / L=$ 1.65 , where $N=2.8 \AA$ and $L=1.7 \AA$ ), which compositionally agrees well with the ZrO suboxide identified via APT. Based on only FFT examination of grain 1, it is difficult to distinguish between the cubic structure aligned in the [211] direction with lattice parameter $4.85 \AA$ and the tetragonal structure aligned in the 

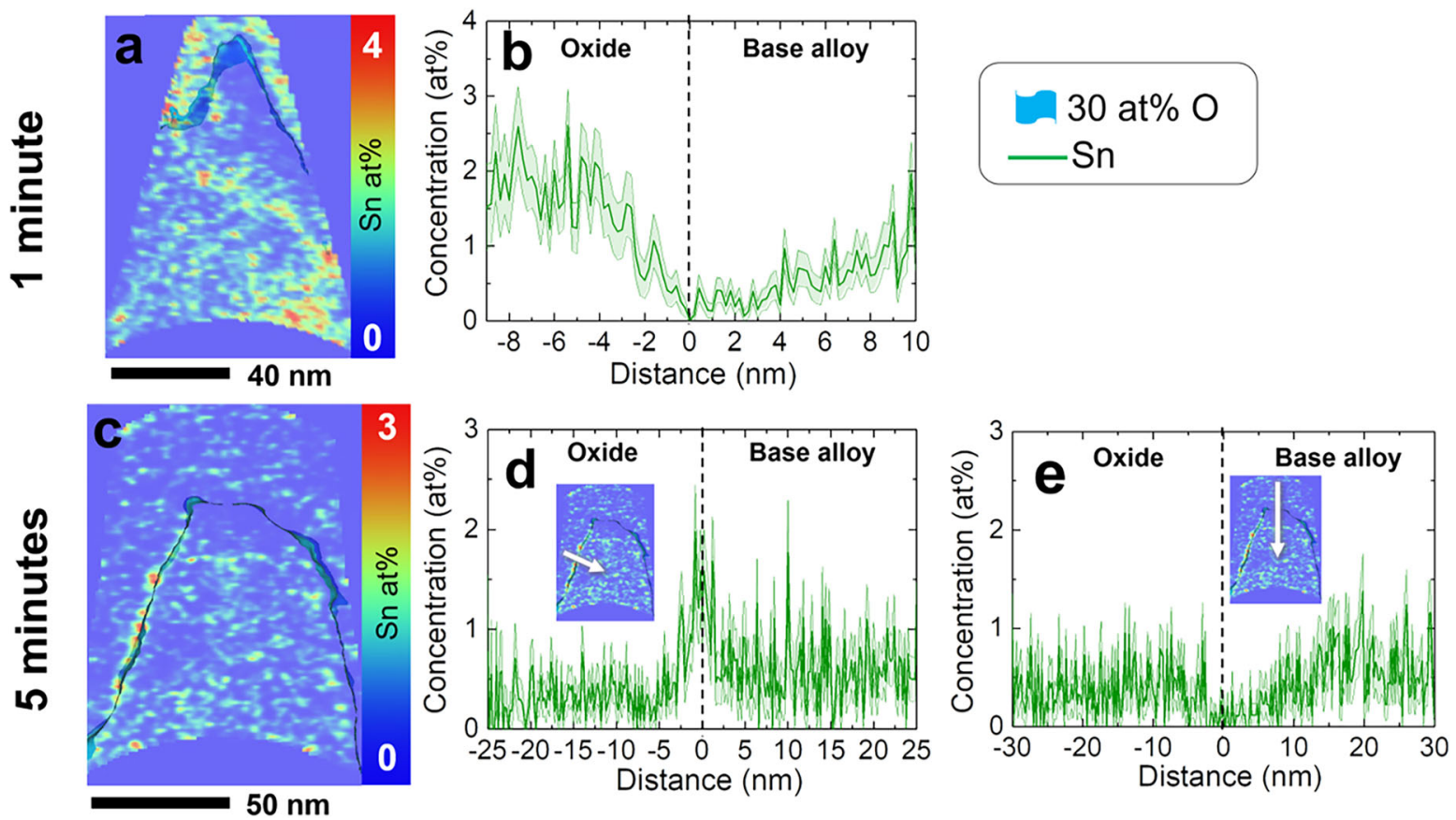

Fig. 5 Redistribution of $\mathrm{Sn}$ after 1 and $5 \mathrm{~min}$ of oxidation at $300^{\circ} \mathrm{C}-10.35 \mathrm{mbar} \mathrm{O}_{2}$. a 2-D Sn concentration map after oxidation for $1 \mathrm{~min}$ and $\mathbf{b}$ 1-D concentration profile across the oxide/metal interface, highlighting the change in Sn concentration. c 2-D Sn concentration map after oxidation for $5 \mathrm{~min}$ and d, e corresponding 1-D concentration profiles across the oxide/metal interface, highlighting the change in Sn concentration. Cylinder placements from which the concentration profile plots were generated are shown as insets in d, e. $30^{\circ}$ at. \% $\mathrm{O}$ isoconcentration surfaces are overlaid in $\mathbf{a}, \mathbf{c}$ and insets of $\mathbf{d}$, e show the location of the oxide/metal interface.

[011] direction with lattice parameters $a=3.40 \AA$ and $c=4.93 \AA$. The analysed grain close to the outermost surface of the needle sample (grain 2 in Fig. 4g) matches the tetragonal crystal structure, which agrees well with the $\mathrm{ZrO}_{2}$ composition (Fig. 3). The grain was consistently indexed as tetragonal structure aligned in the [011] direction ( $N / L=1.68$, where $N=3.10$ and $L=1.84)$ with lattice parameters close to $a=3.68 \AA$ and $c=5.75 \AA$. Note that the extra reflections observed at $(\overline{1} 00)$ locations are kinematically forbidden but can be expected due to dynamic scattering. A wide range of lattice parameters for $\mathrm{Zr}$ oxide phases have been reported in the literature. Lattice parameters commonly reported for the $\mathrm{m}-\mathrm{ZrO}_{2}$ (monoclinic) are $a=5.1690 \AA, b=5.2103 \AA$, and $c=5.3106 \AA$ and for $\mathrm{t}-\mathrm{ZrO}_{2}$ (tetragonal) are $a=3.6070 \AA$ and $c=$ $5.1660 \AA^{42}$. In our results, we do not see a clear indication of $\mathrm{m}$ $\mathrm{ZrO}_{2}$ after $5 \mathrm{~min}$ of oxidation. The outermost region corresponds to $\mathrm{t}-\mathrm{ZrO}_{2}$.

Redistribution of Sn during oxidation

Tin (Sn) is the major alloying element in Zircaloy-4, and its distributions after 1 and 5 min of oxidation are presented using 2$\mathrm{D}$ concentration maps of $\mathrm{Sn}$ and one-dimensional (1-D) concentration profiles in Fig. 5. We observed a heterogeneous distribution of Sn with local enrichments up to 4 at. \% after $1 \mathrm{~min}$ of oxidation (Fig. 5a). A 1-D concentration profile in Fig. 5b from the same condition indicates enrichment of $\mathrm{Sn}$ within oxide $(\sim 2.5$ at. $\%$ ), with a Sn-depleted region of $\sim 5 \mathrm{~nm}$ wide ( $\mathrm{Sn}<0.5$ at. \%) in the base alloy adjacent to the oxide/metal interface. Interestingly, after 5 min of oxidation, we observed a redistribution of Sn across different oxide/metal interface facets. Sn appears to either preferentially segregate at the oxide/metal interface ( 2 at. \%) or show a depletion (e.g. Fig. $5 \mathrm{~d}$ versus Fig. $5 \mathrm{e}$ ). This observation suggests that crystallographic features influence local segregation of $\mathrm{Sn}$ at the oxide/metal interface.

The $\mathrm{Sn}$ distribution inside the oxide layer after 5-min oxidation is shown in Fig. 6. The 2-D Sn concentration maps from several locations, consisting of 1 -nm-thick rectangular slices from the

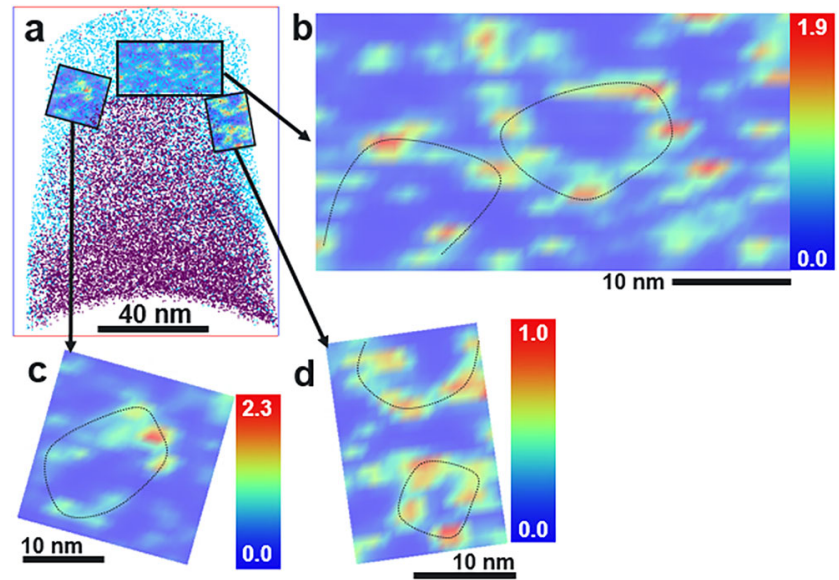

Fig. 6 Distribution of $\mathrm{Sn}$ in the oxide layer after oxidation at $300^{\circ} \mathrm{C}-10.35 \mathrm{mbar}-\mathbf{5} \mathrm{min}$. a APT reconstruction with overlaid locations of 2-D concentration maps from oxide b-d shows magnified 2-D Sn concentration maps inside the oxide. A slice thickness of $1 \mathrm{~nm}$ was used, from which the Sn 2-D concentration maps were determined. Colour scale for each 2-D map shows the range of $\mathrm{Sn}$ concentration variation.

oxide layer (Fig. $6 \mathrm{~b}-\mathrm{d}$ ), reveal local variation of Sn concentration ranging from 0 to 2.3 at. \%. The heterogeneous enrichment of $\mathrm{Sn}$ outlines nanocrystalline oxide grain boundaries, as seen in the high-resolution TEM image in Fig. 4d. The grain size was measured to be $5-10 \mathrm{~nm}$ in TEM, which is consistent with the size of Sn-free regions enclosed within the Sn-rich regions observed here.

XANES analysis of changes in electronic structure of oxide layer $\mathrm{O} K$-edge total fluorescence yield XANES was used to study the changes in electronic structure of the surface of Zircaloy- 4 in the 


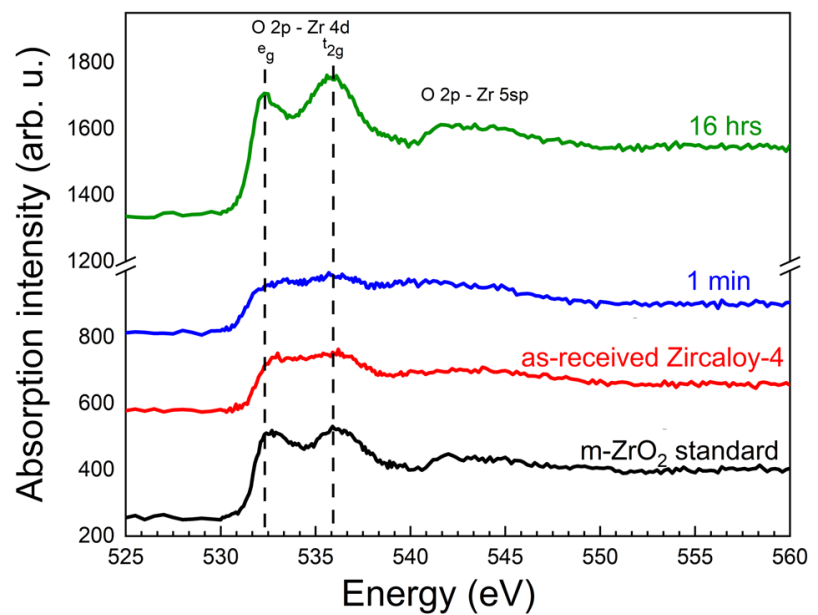

Fig. 7 Synchrotron-based $O$ K-edge XANES spectra for Zircaloy-4 samples. A monoclinic $\mathrm{ZrO}_{2}$ standard compared with as-received Zircaloy-4, and Zircaloy-4 oxidised at $300^{\circ} \mathrm{C}$ and 10.35 mbar for $1 \mathrm{~min}$ and $16 \mathrm{~h}$.

as-received condition and after oxidation at $300^{\circ} \mathrm{C}-10.35 \mathrm{mbar}$ for $1 \mathrm{~min}$ to $16 \mathrm{~h}$. Figure 7 shows absorption intensity versus energy for Zircaloy- 4 oxidised for $1 \mathrm{~min}$ and $16 \mathrm{~h}$ overlaid with a standard $\mathrm{m}-\mathrm{ZrO}_{2}$ sample and unoxidised Zircaloy-4. Spectral features contain two regions describing different electronic transitions: (1) $\mathrm{O} 2 p$ hybridised with $\mathrm{Zr} 4 d$, and (2) $\mathrm{O} 2 p$ hybridised with $\mathrm{Zr}$ $5 s p^{43}$. In the first transition region, two peaks $\left(e_{g}\right.$ and $\left.t_{2 g}\right)$ are seen in both the 16-h oxidised sample and the $\mathrm{m}-\mathrm{ZrO}_{2}$ standard. These two peaks at the $\mathrm{O} K$-edge are attributed to hybridisation of $\mathrm{O} 2 p$ states with $\mathrm{Zr} 4 d-e_{g}$ and $4 d-t_{2 g}$ states ${ }^{44}$. At energies $>540 \mathrm{eV}$, broad spectral features (corresponding to $\mathrm{O} 2 p$ and $\mathrm{Zr} 5 s p$ interactions) are observed for each oxidation condition and the $\mathrm{m}-\mathrm{ZrO}_{2}$ standard. The $\mathrm{O} 2 p-\mathrm{Zr} 5 s p$ spectral features are known to be related to hybridisation ${ }^{45}$, where similar spectra are observed for all sample conditions. This similarity in the post-edge regime suggests that there are no considerable changes in hybridisation for different $\mathrm{Zr}$ oxide structures, consistent with prior work ${ }^{46}$. Results clearly show a change in electronic structure as a function of oxidation conditions. The spectra for unoxidised Zircaloy-4 and Zircaloy- 4 oxidised for $1 \mathrm{~min}$ do not match the $\mathrm{O} K$-edge spectra of the $\mathrm{m}-\mathrm{ZrO}_{2}$. Only after 16 -h oxidisation do the spectra resemble the $\mathrm{m}-\mathrm{ZrO}_{2}$ standard. This result suggests that mixed metastable suboxides are present after short oxidation time steps, which is consistent with the APT and STEM results.

\section{DISCUSSION}

In this study, APT, STEM, and XANES were used to investigate the multiple atomic-level changes that occur across oxide/metal interfaces and within the oxide during the early stages of Zircaloy-4 oxidation. The composition and structure (crystal and electronic) changes that occur during the initial stages of oxidation are of particular importance for Zircaloy-4 because this alloy experiences cyclic oxidation kinetics. Hence, these initial stages of oxidation may occur multiple times throughout a material's lifetime in an oxidising environment. This approach developed and applied to studying Zircaloy-4 oxidation provides insight both into the initial changes accompanying oxidation and demonstrates a methodology for assessing such changes in accelerated time scales than available using traditional long-term experiments in autoclave or dry oxidation environments.

Prior to analysis of oxides formed after $300^{\circ} \mathrm{C}$ oxidation, we identified a thin native oxide layer on APT needle samples comprising $\sim 30$ at. \% O, with stoichiometry close to $\mathrm{Zr}_{3} \mathrm{O}$. This native oxide was removed by field evaporating the needle in APT past the oxide layer. Then the needle was transferred in vacuum to the reaction chamber and oxidation was performed at $300^{\circ} \mathrm{C}$ to investigate structural and compositional changes that occur during oxidation. After 1 min of oxidation at $300^{\circ} \mathrm{C}-10.35 \mathrm{mbar}$ $\mathrm{O}_{2}$, a ZrO layer was formed. After $5 \mathrm{~min}$ at $300^{\circ} \mathrm{C}-10.35 \mathrm{mbar}_{2}$, a $\mathrm{ZrO}$ layer formed adjacent to the metal/oxide interface, followed by suboxides with a stoichiometry of $\mathrm{ZrO}_{2-x}(0<x<1)$, and a tetragonal structured $\mathrm{ZrO}_{2}$ layer formed as the dominant outer oxide layer. Figure $8 \mathrm{a}-\mathrm{c}$ shows sections of the APT reconstruction after 5 -min oxidation at $300^{\circ} \mathrm{C}-10.35$ mbar, where Fig. $8 \mathrm{~d}$ is a schematic representation of the multilayered film. The oxide layer contained equiaxed, nanocrystalline grains, which could be a result of oxide grains nucleating on several surface defects ${ }^{47}$. The $\mathrm{Zr}$ suboxides appear to retain an epitaxial relationship with the base alloy, which has lattice parameters slightly larger than ones reported in the literature. Larger lattice parameters may be attributed to oxygen atoms occupying interstitial sites in the lattice of the HCP base alloy. The tetragonal $\mathrm{ZrO}_{2}$ phase is observed in the outermost region of the oxide after $5 \mathrm{~min}$, with no evidence of the stable monoclinic $\mathrm{ZrO}_{2}$. The presence of only the tetragonal phase in the outer oxide may be attributed to insufficient time for the transformation from tetragonal to monoclinic to proceed. It may also be possible for the tetragonal phase to be stabilised in the outer oxide due to a combination of factors detailed in prior work, such as macroscopic compressive stresses, nanoscale oxide grain size, presence of $\mathrm{Sn}$ in the oxide, and oxygen vacancies ${ }^{48-50}$.

Addition of Sn, the major alloying element in Zircaloy-4, is known to improve yield strength and creep resistance via solid solution strengthening but negatively affect oxidation resistance ${ }^{29,31,51}$. During oxidation, $\mathrm{Sn}$ is incorporated into the oxide ${ }^{31}$, which can influence oxide structure and composition ${ }^{51}$. The grain size was measured to be $5-10 \mathrm{~nm}$ in TEM shown in Fig. 4d, which is consistent with the size of Sn-free regions enclosed within the Sn-rich regions observed in APT. Sn segregation to oxide grain boundaries has previously been suggested and may stabilise tetragonal $\mathrm{ZrO}_{2}$ grains ${ }^{31,51}$. The $\mathrm{Sn}$ segregation observed after 5min oxidation at $300^{\circ} \mathrm{C}$ can therefore indicate that a similar phenomenon is evident in experiments performed as part of this work (Fig. 6). These local regions of Sn enrichment are up to $\sim 3$ at $\% \mathrm{Sn}$ and may be precursors to larger Sn clusters $(\sim 20 \mathrm{~nm}$ in diameter) with higher $\mathrm{Sn}$ content that require more time at elevated temperature to develop ${ }^{31}$. The lack of $\mathrm{Sn}$ precipitates observed here may be attributed to the shorter time scales used in oxidation experiments when compared to the longer-term studies performed after several days in a $400{ }^{\circ} \mathrm{C}$ autoclave ${ }^{31}$.

Our results indicate that $\mathrm{Sn}$ is distributed nonuniformly within the base alloy, along the oxide/metal interface, and within the oxide layer. The segregation of $\mathrm{Sn}$ to $\mathrm{ZrO}$ after oxidation for just $1 \mathrm{~min}$ (Fig. 2) and subsequent partitioning/depletion of Sn along the oxide/metal interface after $5 \mathrm{~min}$ (Fig. 3) depict the early stages of $\mathrm{Sn}$ partitioning into the oxide, which have not been captured in prior ex situ analyses of corroded $\mathrm{Zr}$ alloys. The multistage oxide growth and associated $\mathrm{Sn}$ redistribution is schematically described in Fig. 8d.

Prior work investigating the relationship between Zircaloy-4 oxidation behaviour and oxygen partial pressure demonstrated that structure changes during the oxidation process in various environments (e.g. oxygen gas, water, steam) did not vary with oxygen partial pressure (via X-ray diffraction analysis) in the pretransition regime ${ }^{52}$. Post-transition, however, oxidation rate is weakly dependent on oxygen partial pressure ${ }^{52}$. Here our analysis is focused in the pre-transition regime, so the oxidation environment is not expected to strongly contribute to any structural or compositional changes of the oxide layer but is expected to affect kinetics. Other important factors contributing to oxidation kinetics in the present study include crystallographic orientation of the base alloy and needle specimen geometry. It is 




Fig. 8 Summary of composition and structure across the oxide/metal interface. a Element distribution after $300^{\circ} \mathrm{C}-10.35 \mathrm{mbar} \mathrm{O}_{2}-5 \mathrm{~min}$ for $\mathrm{Zr}$ (purple dots) and ZrO (light blue dots) ions. b 2-D concentration plot illustrating the $\mathrm{O}$ concentration gradient across the oxide/metal interface. c 2-D concentration plot for Sn. $\mathbf{d}$ Schematic of the nanocrystalline oxide and redistribution of Sn developed after 5 min of oxidation treatment. Here c-ZrO refers to face-centred cubic (FCC) $\mathrm{ZrO}$ phase, $\mathrm{ZrO}_{2-x}$ indicates the region with graded composition, and $\mathrm{t}-\mathrm{ZrO} \mathrm{r}_{2}$ refers to the tetragonal $\mathrm{ZrO}_{2}$ phase.

well established that oxidation rate depends on crystallographic orientation of the metal substrate ${ }^{15,153}$. Here each needle was extracted from the same grain (where Zircaloy-4 grains were $\sim 15-25 \mu \mathrm{m}$ in diameter) and thus are expected to have same orientation. However, the non-uniform penetration of oxygen into the base alloy after 1 and 5 min (Figs. 2 and 3) suggests that different facets may be present on the surface of the needle. Additionally, needle specimen shape has previously been shown via in situ TEM to increase oxidation rate and lead to different oxide thicknesses at the apex and along the shank ${ }^{54}$. The impact of curvature has also been investigated by studying oxide phases developed on flat coupons versus nanoparticles (with similar diameter to an APT needle apex) ${ }^{35,55}$. Substrate geometry (flat versus curved) was found to accelerate kinetics but not impact oxide phases formed.

Metastable suboxides including hexagonal $\mathrm{Zr}_{3} \mathrm{O}$, cubic $\mathrm{ZrO}$, and tetragonal $\mathrm{ZrO}_{2}$ have all been reported to form after exposure to an oxygen-rich environment for a range of times, from $<1$ day $^{56}$ to hundreds of days ${ }^{19,29,30}$ in various environments (aqueous ${ }^{19,27,30}$, steam ${ }^{50,57-59}$, and dry oxygen gas ${ }^{56}$ ). More specifically, pretransition suboxides have previously been reported with thicknesses of 30-80 nm (studied via APT) developed over $\sim 34-90$ days in an aqueous environment ${ }^{19}$. Here a similar oxide thickness of $\sim 20 \mathrm{~nm}$ is developed on the APT-STEM needle specimens in a matter of minutes, with comparable suboxide phase compositions and structures. Owing to the needle geometry, oxidation kinetics is significantly accelerated using the in situ APT approach, allowing us to rapidly assess composition/structure changes occurring during initial stages of Zr alloy oxidation, and effectively reduce the time required for oxidation experiments.

The $\mathrm{ZrO}_{2-x}$ phase with a large lattice parameter identified in our work consisted of much higher $\mathrm{O}$ concentration than the previously reported composition range (40-50 at. \% O) for suboxides with unidentified crystal structure ${ }^{19,60}$. Even though the needle-shaped geometry in the current analysis results in multiple overlapping nanocrystalline grains-making it difficult to unambiguously ascertain the crystal structure of this suboxide layer using STEM-we observe face-centred cubic $\mathrm{ZrO}$ and tetragonal $\mathrm{ZrO}_{2}$ suboxides, consistent with prior work ${ }^{19}$; we find no evidence for hexagonal $\mathrm{Zr}_{3} \mathrm{O}^{19,27,61}$ or monoclinic $\mathrm{ZrO}_{2}$ after oxidation at $300{ }^{\circ} \mathrm{C}$ for up to $5 \mathrm{~min}$ in the current work. We also find variable and significantly lower local oxygen concentration (relative to the $\sim 30$ at. \% solid solubility limit of $O$ in $a-Z r$ ) in the base alloy, ranging from 2 to 20 at. \%, below the oxide-metal interface (see Fig. 3c, d). The differences in the structures and compositions of oxide phases between our experiments and prior work from literature is attributed to our ability to capture very early stages of the oxidation progression that have not been possible to resolve previously.

Quantifying oxide stoichiometry is a significant challenge given the known oxygen deficits in laser-assisted $\mathrm{APT}^{62-65}$. Here the application of complementary microscopic and spectroscopic methods allows us to assign oxide stoichiometries to the phases formed during the in situ experiments. The oxide stoichiometries reported here, in particular the $\mathrm{ZrO}$ and $\mathrm{ZrO}_{2} \mathrm{~m}$, are confirmed by STEM measurements that identified cubic and tetragonal oxide phases (after oxidation at $300^{\circ} \mathrm{C}$ for $5 \mathrm{~min}$ ), which have known stoichiometries of $\mathrm{ZrO}$ and $\mathrm{ZrO}_{2}$, respectively. Hence, we assign the cubic inner oxide to $\mathrm{ZrO}$ and outer oxide to tetragonal $\mathrm{ZrO}_{2}$, and thus the region of composition $\mathrm{ZrO}_{2-x}$ is a transition region between these two known phases. To further investigate error associated with $\mathrm{Zr}$ oxide quantification via APT, standard $\mathrm{ZrO}_{2}$ may be run using similar user-selected parameters.

In this work, structural, compositional, and electronic structure changes during the early stages of Zircaloy-4 oxidation were studied using a multimodal chemical imaging approach. Needle- 
shaped Zircaloy- 4 samples were oxidised at $300{ }^{\circ} \mathrm{C}$ in 10.35 mbar, high-purity $\mathrm{O}_{2}$ gas for 1 and $5 \mathrm{~min}$ in an environmental reaction chamber attached to an APT system. APT and correlative STEM analysis of the oxidised needles permitted a rapid assessment of metastable suboxides, revealing formation of an initial cubic $\mathrm{ZrO}$ layer, followed by a transition layer of $\mathrm{ZrO}_{2-x}$ (with composition and structure previously not reported in literature) and tetragonal $\mathrm{ZrO}_{2}$ as the outermost layer. Sn enrichment into the $\mathrm{ZrO}$ suboxide phase, followed by its segregation to different regions of the oxide/ metal interface, was also observed. XANES analysis of Zircaloy-4 coupons complemented the APT/STEM characterisation and showed that the stable monoclinic oxide did not form until longer oxidation times, on the order of hours. The approach presented here can be valuable for rapidly assessing structure and composition changes during early stages of oxidation in several commercial alloys for oxidation- and corrosion-sensitive applications.

\section{METHODS}

Materials and needle sample preparation

A Zircaloy- 4 tube, with composition $1.02 \pm 0.03 \mathrm{Sn}, 0.72 \pm 0.02 \mathrm{O}, 0.38 \pm$ $0.01 \mathrm{Fe}$, and $0.23 \pm 0.01 \mathrm{Cr}$ (all in at. \%), with balance $\mathrm{Zr}$, was sectioned and ion milled to produce a polished cross-section. Composition specification and impurities are detailed in Supplementary Tables 1-3 and Supplementary Fig. 3. Ion milling was used in lieu of standard metallographic polishing procedures to minimise hydrogen uptake of Zircaloy-4 from aqueous metallographic polishing. Needles for APT and TEM analysis were prepared from the polished cross-section via the standard FIB-based liftout process ${ }^{66}$. Samples were mounted to pre-sharpened tungsten APT/ TEM correlation grids ${ }^{67}$ and silicon microtip arrays for TEM and APT analysis, respectively.

Characterisation of composition and structure via APT and STEM The experimental approach for complementary STEM and APT analysis of oxide and Zircaloy-4 base metal (schematically shown in Supplementary Fig. 4) involves the following steps: (1) needle sample preparation via FIB lift-out method ${ }^{66},(2)$ analysis and removal of the native oxide via APT field evaporation, (3) oxidation of the needle samples in the reaction chamber, and (4) APT or STEM analysis of the oxide layer formed during the oxidation process.

Oxidation of Zircaloy-4 needles was performed in $\mathrm{O}_{2}$ gas $(99.993 \%$ purity) at $10.35 \mathrm{mbar}$ and $300^{\circ} \mathrm{C}$ for 1 or $5 \mathrm{~min}$. Experimental conditions were selected to perform Zircaloy-4 oxidation at temperatures relevant to nuclear reactor applications. Time and pressure parameters were selected to control Zircaloy-4 oxidation so that the oxide/metal interface was captured in the top $\sim 50 \mathrm{~nm}$ of the needle specimen and could then be analysed via APT. After the initial APT analysis and removal of the native oxide, the needle array was transferred under UHV $\left(10^{-7}-10^{-8} \mathrm{mbar}\right)$ to the reaction chamber, where the stage was preheated to $300^{\circ} \mathrm{C}^{68}$. The UHV transfer time from APT to reaction chamber was $<5$ min and prevents any atmospheric exposure during the transfer. Pressure in the reactor prior to oxygen gas exposure was $\sim 10^{-8}$ mbar. Next, $\mathrm{O}_{2}$ gas (which was not preheated) was introduced into the reaction chamber to the desired pressure of $10.35 \mathrm{mbar}$ at a rate of $100 \mathrm{~cm}^{3} / \mathrm{min}$, and the APT needles were exposed to $\mathrm{O}_{2}$ gas for the desired time interval (here 1-5 min). The reactor was then immediately evacuated to remove all gas and return to UHV conditions. The oxidised sample was then moved directly to the APT analysis chamber, which takes $\sim 2 \mathrm{~min}$. In the analysis chamber, the sample was rapidly cooled by placing it on the cryogenically cooled sample stage set to a temperature of $45 \mathrm{~K}$.

A Cameca LEAP 4000X HR system equipped with a $355 \mathrm{~nm}$ wavelength ultraviolet laser was used for all APT data collection with the following user-selected parameters: $125 \mathrm{kHz}$ pulse frequency, $200 \mathrm{pJ} /$ pulse laser energy, $45 \mathrm{~K}$ sample base temperature, and 0.005 detected ions/pulse. All APT data sets were reconstructed and analysed using the Integrated Visualisation and Analysis Software (IVAS), version 3.8.2. Manual ranging was used for analysis of the APT mass spectra. Peak overlaps between Sn isotopes and $\mathrm{Zr}$ oxide molecular species (e.g. $\mathrm{Zr}_{2} \mathrm{O}_{3}$ and $\mathrm{ZrO}_{2}$ ) were seen in mass spectra; these are detailed in Supplementary Fig. 5. Regions of gallium $(\mathrm{Ga})$ implantation from the FIB processing were excluded from the analysed volumes discussed here. Further details on APT data handling, including the $\mathrm{Ga}$ distribution and composition quantifications, are provided in Supplementary Figs. 6-8.

Concentration profiles across different facets of oxide/metal interfaces were quantified using the proximity histogram method via isoconcentration surfaces generated at 30 at. \% O. 2-D concentration plots were also used to quantitatively investigate $\mathrm{O}$ and $\mathrm{Sn}$ composition in the oxide and the base alloy. 2-D concentration plots were generated using a rectangular cross-section $1 \mathrm{~nm}$ thick. Crystallographic and compositional examination of Zircaloy needle samples was done with a probe-corrected FEl Titan 80-300 STEM instrument operated at $300 \mathrm{kV}$. The observations were performed using STEM with a high-angle annular dark-field (HAADF) detector. The probe convergence angle was $18 \mathrm{mrad}$, and the inner detection angle on the HAADF detector was three times larger than the probe convergence angle. AZtec energy dispersive spectroscopy (EDS) software was used to analyse the composition captured by EDS in the STEM instrument.

\section{Electronic structure change characterised via XANES}

The electronic structure changes of an unoxidised Zircaloy- 4 coupon, ones oxidised at $300^{\circ} \mathrm{C}$ for $1 \mathrm{~min}, 5 \mathrm{~min}$, and $16 \mathrm{~h}$, and a $\mathrm{m}-\mathrm{ZrO}_{2}$ standard were analysed using synchrotron-based XANES at Advanced Light Source synchrotron beamline 7.3.1 at Lawrence Berkeley National Laboratory. XANES spectra were collected with an overall resolution of $0.1 \mathrm{eV}$ at the oxygen $\mathrm{K}$-edge. Experiments were conducted in a UHV chamber with a background pressure of $2 \times 10^{-10} \mathrm{mbar}$. Photon energies were varied from 525 to $560 \mathrm{eV}$. Data were acquired in total fluorescence yield and total electron yield to obtain oxidation information at the surface $(<10 \mathrm{~nm})$ and deeper $(<100 \mathrm{~nm})$. The $O K$-edge total fluorescence yield signal was utilised in this work to characterise the top $100 \mathrm{~nm}$ of all samples. Acquired spectra were normalised to background incident intensity.

\section{DATA AVAILABILITY}

The data that support results of the presented study are available from the corresponding author upon reasonable request.

Received: 9 May 2020; Accepted: 7 September 2020; Published online: 25 September 2020

\section{REFERENCES}

1. Martin, T. L. et al. Atomic-scale studies of uranium oxidation and corrosion by water vapour. Sci. Rep. 6, 25618 (2016).

2. Motta, A. T., Couet, A. \& Comstock, R. J. Corrosion of zirconium alloys used for nuclear fuel cladding. Annu. Rev. Mater. Res. 45, 311-343 (2015).

3. Osei-Agyemang, E. \& Balasubramanian, G. Surface oxidation mechanism of a refractory high-entropy alloy. npj Mater. Degrad. 3, 20 (2019).

4. Pflumm, R., Donchev, A., Mayer, S., Clemens, H. \& Schütze, M. High-temperature oxidation behavior of multi-phase Mo-containing $\mathrm{Y}$-TiAl-based alloys. Intermetallics 53, 45-55 (2014).

5. Li, T., Marquis, E. A., Bagot, P. A. J., Tsang, S. C. \& Smith, G. D. W. Characterization of oxidation and reduction of a platinum-rhodium alloy by atom-probe tomography. Catal. Today 175, 552-557 (2011).

6. Lambeets, S. V., Visart de Bocarmé, T., Perea, D. E. \& Kruse, N. Directional gateway to metal oxidation: 3D chemical mapping unfolds oxygen diffusional pathways in rhodium nanoparticles. J. Phys. Chem. Lett. 11, 3144-3151 (2020).

7. Pedrazzini, S. et al. In-service oxidation and microstructural evolution of a nickel superalloy in a formula 1 car exhaust. Oxid. Met. 89, 375-394 (2018).

8. Tuominen, $M$. et al. Oxidation-induced changes in the $A L D-\mathrm{Al}_{2} \mathrm{O}_{3} / \ln \mathrm{As}(100)$ interface and control of the changes for device processing. ACS Appl. Mater. Interfaces 10, 44932-44940 (2018).

9. Zhao, D., Tian, C., Tang, S., Liu, Y. \& Chen, L. High temperature oxidation behavior of cobalt triantimonide thermoelectric material. J. Alloy. Compd. 504, 552-558 (2010).

10. Blades, W. H. \& Reinke, P. From alloy to oxide: capturing the early stages of oxidation on Ni-Cr(100) alloys. ACS Appl. Mater. Interfaces 10, 43219-43229 (2018).

11. Luo, L. et al. In situ atomic scale visualization of surface kinetics driven dynamics of oxide growth on a Ni-Cr surface. Chem. Commun. 52, 3300-3303 (2016).

12. Lemaignan, C. \& Motta, A. T. in Materials Science and Technology (eds Cahn, R. W., Haasen, P. \& Kramer, E. J.) Ch. 7 (Wiley, 2006).

13. Rickover, H. G., Geiger, L. D. \& Lustman, B. History of the Development of Zirconium Alloys for Use in Nuclear Reactors (International Atomic Energy Agency, 1975). 
14. Reid, B. D. \& Lanning, D. D. Tritium-producing burnable absorber rod and its inherent safety features. Trans. Am. Nucl. Soc. 82, 285 (2000).

15. Luscher, W. G., Senor, D. J., Clayton, K. K. \& Longhurst, G. R. In-reactor oxidation of zircaloy-4 under low water vapor pressures. J. Nucl. Mater. 456, 17-22 (2015).

16. Douglass, D. L. Metallurgy of Zirconium (International Atomic Energy Agency, 1971)

17. Duan, Z. et al. Current status of materials development of nuclear fuel cladding tubes for light water reactors. Nucl. Eng. Des. 316, 131-150 (2017).

18. Sayers, J., Lozano-Perez, S., Nicholls, R. J. \& Ortner, S. A high-resolution characterization of the oxide-metal interface in Zircaloy- 4 and its relation to the oxidation and hydrogen pickup mechanisms. J. Nucl. Mater. 525, 72-82 (2019).

19. Ni, N. et al. How the crystallography and nanoscale chemistry of the metal/oxide interface develops during the aqueous oxidation of zirconium cladding alloys. Acta Mater. 60, 7132-7149 (2012).

20. Beie, H.-J., Mitwalsky, A., Garzarolli, F., Ruhmann, H. \& Sell, H.-J. Examinations of the corrosion mechanism of zirconium alloys. In Zirconium in the Nuclear Industry: Tenth International Symposium (eds Bradley, E. \& Sabol, G.) 615-643 (ASTM International, 1994).

21. Pecheur, D., Godlewski, J., Billot, P. \& Thomazet, J. Microstructure of oxide films formed during the waterside corrosion of the Zircaloy-4 cladding in lithiated environment. In Zirconium in the Nuclear Industry: Eleventh International Symposium (eds Bradley, E. \& Sabol, G.) 94-113 (ASTM International, 1996).

22. Motta, A. et al. Microstructural characterization of oxides formed on model $\mathrm{Zr}$ alloys using synchrotron radiation. J. ASTM Int. 5, 1-20 (2008).

23. Ahmed, T. \& Keys, L. H. The breakaway oxidation of zirconium and its alloys a review. J. Less Common Met. 39, 99-107 (1975).

24. Glazoff, M., Tokuhiro, A., Rashkeev, S. \& Sabharwall, P. Oxidation and hydrogen uptake in zirconium, Zircaloy-2 and Zircaloy-4: computational thermodynamics and ab initio calculations. J. Nucl. Mater. 444, 65-75 (2014).

25. Cox, B. Processes occurring during the breakdown of oxide films on zirconium alloys. J. Nucl. Mater. 29, 50-66 (1969).

26. Young, D. J. High Temperature Oxidation and Corrosion of Metals (Elsevier, 2008).

27. De Gabory, B., Dong, Y., Motta, A. T. \& Marquis, E. A. EELS and atom probe tomography study of the evolution of the metal/oxide interface during zirconium alloy oxidation. J. Nucl. Mater. 462, 304-309 (2015).

28. de Gabory, B., Motta, A. T. \& Wang, K. Transmission electron microscopy characterization of Zircaloy-4 and ZIRLO ${ }^{\text {TM }}$ oxide layers. J. Nucl. Mater. 456, 272-280 (2015).

29. Dong, Y., Motta, A. T. \& Marquis, E. A. Atom probe tomography study of alloying element distributions in $\mathrm{Zr}$ alloys and their oxides. J. Nucl. Mater. 442, 270-281 (2013).

30. Dong, Y., Motta, A. T. \& Marquis, E. A. Multi-scale characterization of oxidized zirconium alloys. Microsc. Microanal. 22, 1496-1497 (2016)

31. Sundell, G., Thuvander, M. \& Andrén, H. O. Tin clustering and precipitation in the oxide during autoclave corrosion of Zircaloy-2. J. Nucl. Mater. 456, 409-414 (2015).

32. Yilmazbayhan, A., Breval, E., Motta, A. T. \& Comstock, R. J. Transmission electron microscopy examination of oxide layers formed on $\mathrm{Zr}$ alloys. J. Nucl. Mater. 349, 265-281 (2006)

33. Yilmazbayhan, A. et al. Structure of zirconium alloy oxides formed in pure water studied with synchrotron radiation and optical microscopy: relation to corrosion rate. J. Nucl. Mater. 324, 6-22 (2004).

34. Luo, L. et al. In-situ transmission electron microscopy study of surface oxidation for $\mathrm{Ni}-10 \mathrm{Cr}$ and $\mathrm{Ni}-20 \mathrm{Cr}$ alloys. Scr. Mater. 114, 129-132 (2016).

35. Wang, C.-M., Schreiber, D. K., Olszta, M. J., Baer, D. R. \& Bruemmer, S. M. Direct in situ TEM observation of modification of oxidation by the injected vacancies for Ni-4Al alloy using a microfabricated nanopost. ACS Appl. Mater. Interfaces 7, 17272-17277 (2015).

36. Bagot, P. A. J., Visart de Bocarmé, T., Cerezo, A. \& Smith, G. D. W. 3D atom probe study of gas adsorption and reaction on alloy catalyst surfaces I: Instrumentation. Surf. Sci. 600, 3028-3035 (2006).

37. Li, T., Bagot, P. A. J., Marquis, E. A., Tsang, S. C. E. \& Smith, G. D. W. Characterization of oxidation and reduction of $\mathrm{Pt}-\mathrm{Ru}$ and $\mathrm{Pt}-\mathrm{Rh}-\mathrm{Ru}$ alloys by atom probe tomography and comparison with Pt-Rh. J. Phys. Chem. C 116, 17633-17640 (2012).

38. McCarroll, I. E. et al. The effect of hydrogen on the early stages of oxidation of a magnesium alloy. Corros. Sci. 165, 108391 (2020).

39. Lambeets, S. V., Kautz, E. J., Wirth, M. G., Orren, G. J., Devaraj, A. \& Perea, D. E. Nanoscale perspectives of metal degradation via in situ atom probe tomography. Top. Cat. S https://doi.org/10.1007/s11244-020-01367-z.

40. Abriata, J. P., Garcés, J. \& Versaci, R. The O-Zr (oxygen-zirconium) system. Bull. Alloy Phase Diagr. 7, 116-124 (1986).

41. Steuwer, A. et al. Evidence of stress-induced hydrogen ordering in zirconium hydrides. Acta Mater. 57, 145-152 (2009).
42. Gauna, M. R. et al. Monoclinic-tetragonal zirconia quantification of commercial nanopowder mixtures by XRD and DTA. Ceram. Silik. 59, 318-325 (2015).

43. Rawat, M. et al. Micro-Raman and electronic structure study on kinetics of electronic excitations induced monoclinic-to-tetragonal phase transition in zirconium oxide films. RSC Adv. 6, 104425-104432 (2016).

44. Varshney, M., Sharma, A., Chae, K. H., Kumar, S. \& Won, S. O. Electronic structure and dielectric properties of $\mathrm{ZrO} 2-\mathrm{CeO} 2$ mixed oxides. J. Phys. Chem. Solids 119, 242-250 (2018).

45. Soriano, L. et al. The O-1s X-ray-absorption spectra of transition-metal oxides - the $\mathrm{TiO}_{2}-\mathrm{ZrO}_{2}-\mathrm{HfO}_{2}$ and $\mathrm{V}_{2} \mathrm{O}_{5}-\mathrm{Nb}_{2} \mathrm{O}_{5}-\mathrm{Ta}_{2} \mathrm{O}_{5}$ series. Solid State Commun. 87, 699-703 (1993).

46. Kikas, A. et al. Effect of phase composition on X-ray absorption spectra of $\mathrm{ZrO} 2$ thin films. J. Electron Spectrosc. Relat. Phenom. 156-158, 303-306 (2007)

47. Sabol, G. P., McDonald, S. G. \& Airey, G. P. in Zirconium in Nuclear Applications (eds Schemel, J. \& Rosenbaum, H.) 435-448 (ASTM International, 1974).

48. Pétigny, N., Barberis, P., Lemaignan, C., Valot, C. \& Lallemant, M. In situ XRD analysis of the oxide layers formed by oxidation at $743 \mathrm{~K}$ on Zircaloy 4 and Zr-1NbO. J. Nucl. Mater. 280, 318-330 (2000).

49. Oskarsson, M., Ahlberg, E., Andersson, U. \& Pettersson, K. Characterisation of pretransition oxides on Zircaloys. J. Nucl. Mater. 297, 77-88 (2001).

50. Zhang, H. X. et al. Crystal structure, corrosion kinetics of new zirconium alloys and residual stress analysis of oxide films. J. Nucl. Mater. 396, 65-70 (2010).

51. Wei, J. et al. The effect of $\mathrm{Sn}$ on autoclave corrosion performance and corrosion mechanisms in Zr-Sn-Nb alloys. Acta Mater. 61, 4200-4214 (2013).

52. Nakamura, J., Hashimoto, M., Otomo, T. \& Kawasaki, S. Effects of oxygen partial pressure on oxidation of Zircaloy. J. Nucl. Mater. 200, 256-264 (1993).

53. Boggs, W. E., Kachik, R. H. \& Pellissier, G. E. The effects of crystallographic orientation and oxygen pressure on the oxidation of iron. J. Electrochem. Soc. 114, 32 (1967).

54. Stott, F. H. The protective action of oxide scales in gaseous environments at high temperature. Rep. Prog. Phys. 50, 861 (1987).

55. Wang, C. M. et al. Void formation during early stages of passivation: initial oxidation of iron nanoparticles at room temperature. J. Appl. Phys. 98, 094308 (2005).

56. Bespalov, I. et al. Initial stages of oxide formation on the $\mathrm{Zr}$ surface at low oxygen pressure: an in situ FIM and XPS study. Ultramicroscopy 159, 147-151 (2015).

57. Anada, H. \& Takeda, K. Microstructure of oxides on Zircaloy-4, $1.0 \mathrm{Nb}$ Zircaloy-4, and Zircaloy-2 formed in 10.3-MPa steam at $673 \mathrm{~K}$. In Zirconium in the Nuclear Industry: Eleventh International Symposium (eds Bradley, E. \& Sabol, G.) 35-54 (ASTM International, 1996)

58. Baek, J. H. \& Jeong, Y. H. Steam oxidation of $\mathrm{Zr}-1.5 \mathrm{Nb}-0.4 \mathrm{Sn}-0.2 \mathrm{Fe}-0.1 \mathrm{Cr}$ and Zircaloy-4 at $900-1200^{\circ} \mathrm{C}$. J. Nucl. Mater. 361, 30-40 (2007)

59. Guilbert, S. et al. in Zirconium in the Nuclear Industry, Vol. 17 (eds Comstock, B. \& Barberis, P.) 952-978 (ASTM International, 2015).

60. Kim, H.-G., Park, J.-Y., Choi, B.-K. \& Jeong, Y.-H. Evaluation of pre-transition oxide on Zr-0.4 Nb alloy by using the HVEM. J. Nucl. Mater. 374, 204-210 (2008).

61. Moseley, P. T. \& Hudson, B. Phases involved in the corrosion of zircaloy by hot water $\left(350^{\circ} \mathrm{C}\right)$. J. Nucl. Mater. 99, 340-344 (1981).

62. Gault, B. et al. Behavior of molecules and molecular ions near a field emitter. N. J. Phys. 18, 033031 (2016).

63. Karahka, M., Xia, Y. \& Kreuzer, H. J. The mystery of missing species in atom probe tomography of composite materials. Appl. Phys. Lett. 107, 062105 (2015).

64. Bachhav, M., Danoix, F., Hannoyer, B., Bassat, J. M. \& Danoix, R. Investigation of O18 enriched hematite ( $\mathrm{a}-\mathrm{Fe} 2 \mathrm{O} 3$ ) by laser assisted atom probe tomography. Int. J. Mass Spectrom. 335, 57-60 (2013).

65. Devaraj, A., Colby, R., Hess, W. P., Perea, D. E. \& Thevuthasan, S. Role of photoexcitation and field ionization in the measurement of accurate oxide stoichiometry by laser-assisted atom probe tomography. J. Phys. Chem. Lett. 4, 993-998 (2013).

66. Devaraj, A. et al. Three-dimensional nanoscale characterisation of materials by atom probe tomography. Int. Mater. Rev. 63, 68-101 (2018).

67. Felfer, P. J., Alam, T., Ringer, S. P. \& Cairney, J. M. A reproducible method for damage-free site-specific preparation of atom probe tips from interfaces. Microsc. Res. Tech. 75, 484-491 (2012).

68. Perea, D. E., Gerstl, S. S. A., Chin, J., Hirschi, B. \& Evans, J. E. An environmental transfer hub for multimodal atom probe tomography. Adv. Struct. Chem. Imaging 3, 12 (2017)

\section{ACKNOWLEDGEMENTS}

This work was supported by the open call Laboratory Directed Research and Development programme at Pacific Northwest National Laboratory (PNNL). The Zircaloy-4 material was obtained from the U.S. Department of Energy (DOE) National Nuclear Security Administration under the tritium science programme. Initial 
development of the experimental approach for needle sample preparation in FIB and transfer for studying oxidation of Zircaloy was also funded by the tritium science programme. A portion of this research was performed using facilities at the Environmental Molecular Sciences Laboratory, a national scientific user facility sponsored by the DOE Office of Biological and Environmental Research and located at PNNL. The authors thank S. China. for helpful discussion and manuscript review. Additionally, the authors thank M. Elmore and B. Johnson of PNNL for helping with sample preparation and all the other staff directly or indirectly associated with producing the results featured in this publication. The XANES analysis was conducted at beamline 7.3.1 at the Advanced Light Source at Lawrence Berkeley National Laboratory, a national user facility. The beamline is supported by the Director, Office of Science, Office of Basic Energy Sciences of the U.S. DOE. PNNL is operated for the U.S. DOE by Battelle Memorial Institute under Contract No. DE-AC05-76RLO1830.

\section{AUTHOR CONTRIBUTIONS}

E.J.K. performed all sample preparation, atom probe data collection, and analysis under the mentorship of A.D., D.K.S., and D.E.P. B.G. performed all TEM data collection and analysis with guidance from L.K. S.V.M.L. and D.E.P. assisted with execution of oxidation experiments. K.-P.T. collected XANES data, and A.K.B. analysed XANES data. E.J.K. led manuscript writing, and all authors contributed to the discussion of results and manuscript preparation. A.D. conceptualised and directed the work presented here.

\section{COMPETING INTERESTS}

The authors declare no competing interests.

\section{ADDITIONAL INFORMATION}

Supplementary information is available for this paper at https://doi.org/10.1038/ s41529-020-00133-6.

Correspondence and requests for materials should be addressed to A.D.

Reprints and permission information is available at http://www.nature.com/ reprints

Publisher's note Springer Nature remains neutral with regard to jurisdictional claims in published maps and institutional affiliations.

Open Access This article is licensed under a Creative Commons Attribution 4.0 International License, which permits use, sharing, adaptation, distribution and reproduction in any medium or format, as long as you give appropriate credit to the original author(s) and the source, provide a link to the Creative Commons license, and indicate if changes were made. The images or other third party material in this article are included in the article's Creative Commons license, unless indicated otherwise in a credit line to the material. If material is not included in the article's Creative Commons license and your intended use is not permitted by statutory regulation or exceeds the permitted use, you will need to obtain permission directly from the copyright holder. To view a copy of this license, visit http://creativecommons. org/licenses/by/4.0/.

This is a U.S. government work and not under copyright protection in the U.S.; foreign copyright protection may apply 2020 